\title{
Competências digitais dos professores:
}

da autoavaliação da práxis às necessidades formativas

Digital competence of educators: from praxis self-assessment to training needs

Competencias digitales del profesorado: de la autoevaluación de la praxis a las necesidades formativas
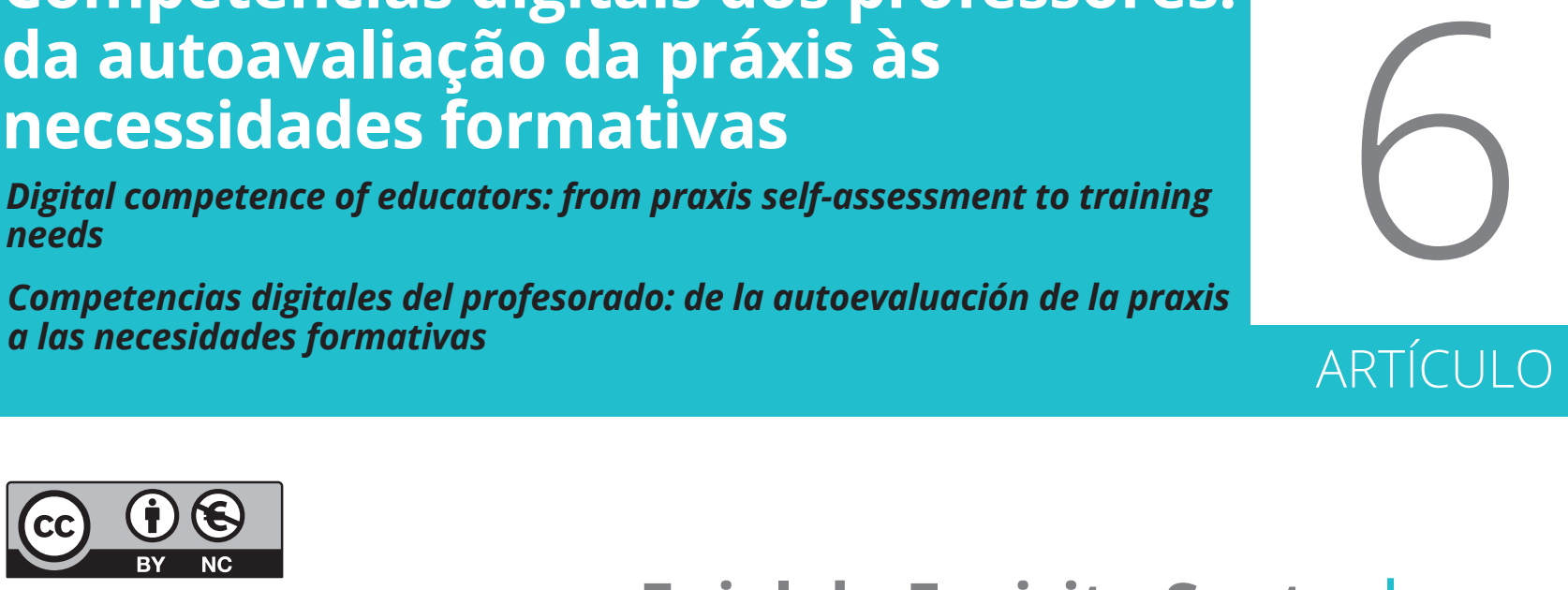

\section{Eniel do Espirito Santo}

Universidade Federal do Recôncavo da Bahia (Brasil)

Doutor em Educação. Professor no Centro de Cultura, Linguagens e Tecnologias Aplicadas (CECULT) da Universidade Federal do Recôncavo da Bahia (UFRB), Brasil. Coordenador adjunto do Sistema Universidade Aberta do Brasil na UFRB. Pesquisador com investigações em Didática e Inovação Pedagógica e Tecnologias Digitais na Educação. Avaliador do Sistema Nacional de Avaliação da Educação Superior do Ministério da Educação.

eniel@ufrb.edu.br

orcid.org/0000-0003-0589-1298

\section{Tatiana Polliana Pinto de Lima}

Universidade Federal do Recôncavo da Bahia (Brasil)

Doutora em Educação. Professora de cursos de Graduação e de Pós-Graduação nas linhas de Saberes e Práticas Docentes, Formação de Professores e Inovação Pedagógica. Avaliadora do Sistema Nacional de Avaliação da Educação Superior e do Programa Nacional do Livro Didático, ambos do Ministério da Educação. Avaliadora Ad-hoc do CNPq/MEC/Brasil.

tatianalima@ufrb.edu.br

orcid.org/0000-0003-2896-5616

\section{Adriano Dantas de Oliveira}

Universidade Federal do Recôncavo da Bahia (Brasil)

Doutor em Filologia e Língua Portuguesa. Professor e pesquisador nas linhas de Didática e Inovação Pedagógica e Retórica e Semiótica aplicada à canção.

adriano.dantas@ufrb.edu.br

orcid.org/ 0000-0002-2146-634X

RECIBIDO: 01 de maio de 2021 / ACEPTADO: 20 de agosto de 2021 


\section{Resumo}

A atual sociedade conectada demanda dos professores competências digitais no seu fazer pedagógico. Este estudo analisa as competências digitais requeridas para os professores, baseando-se no quadro comum para a autoavaliação das competências digitais dos professores (DigCompEdu). Com abordagem quantitativa, aplicamos a escala de autoavaliação DigCompEdu Checkln com 145 professores brasileiros dos Anos Iniciais do Ensino Fundamental. Os professores alcançaram escore de 40,9 pontos, classificando-os como B1 - Integrador, revelando lacunas nas suas competências profissionais e pedagógicas, bem como no desenvolvimento das competências discentes. Urge que a formação docente contemple o uso pedagógico das tecnologias como promotoras da aprendizagem e emancipação dos estudantes.

\section{PALAVRAS-CHAVE}

Competências digitais, Professores, DigCompEdu, Formação docente.

\section{Abstract}

Today's connected society demands digital competence from teachers in their pedagogical work. This study analyzes the digital competence required for teachers, based on the common self-assessment framework of digital competence of teachers (DigCompEdu). Using a quantitative approach, the DigCompEdu Checkln self-assessment scale was applied to 145 Brazilian teachers in the first years of primary school. The teachers obtained a score of 40.9 points, classifying them as B1 - Integrative, revealing gaps in their professional and pedagogical competence, as well as in the development of the competence of the students. It is urgent that teacher training includes the pedagogical use of technologies as drivers of learning and the emancipation of students.

\section{KEYWORDS}

Digital competence, Teachers, DigCompEdu, Teacher training.

\section{Resumen}

La actual sociedad conectada exige competencias digitales a los docentes en su labor pedagógica. Este estudio analiza las competencias digitales requeridas para los docentes, a partir del marco común de autoevaluación de las competencias digitales de los docentes (DigCompEdu). Con un enfoque cuantitativo, se aplicó la escala de autoevaluación DigCompEdu Checkln a 145 docentes brasileños de los primeros años de la escuela primaria. Los docentes obtuvieron una puntuación de 40,9 puntos, clasificándolos como B1 - Integrador, revelando brechas en sus competencias profesionales y pedagógicas, así como en el desarrollo de las competencias de los estudiantes. Es urgente que la formación docente incluya el uso pedagógico de las tecnologías como impulsoras del aprendizaje y la emancipación de los estudiantes.

\section{PALABRAS CLAVE}

Competencias digitales, Docentes, DigCompEdu, Formación docente. 


\section{INTRODUÇÃO}

A pandemia da Covid-19, originada pelo coronavírus SARS Cov-2, arremessou professores e instituições de ensino de todo o mundo para os espaços virtuais de aprendizagem, demandando-lhes o desenvolvimento ou aprimoramento de competências digitais visando a continuidade das atividades educativas em meio ao caos da crise sanitária ocasionada pela pandemia.

Nesse contexto disruptivo, saber utilizar as potencialidades pedagógicas das tecnologias digitais tornou-se condição sine qua non para os docentes, especialmente ao se considerar as especificidades metodológicas do ensino online e, sobretudo, evitar a mera transposição das práticas pedagógicas do espaço escolar presencial para o "universo" virtual.

Destaca-se que a necessidade da utilização das tecnologias digitais como suporte à mediação pedagógica no processo de ensino e aprendizagem antecede às demandas da pandemia Covid-19. Importante relembrar, neste contexto, que os debates, nos idos dos anos 1990, no Brasil, acerca das "Novas Tecnologias da Educação", denominadas posteriormente de "Tecnologias Digitais de Informação e Comunicação", não chegaram em sua inteireza às unidades escolares da Educação Básica, por meio da formação continuada ou mesmo da preparação inicial, oriunda dos cursos de formação docente das Universidades brasileiras.

Por outro lado, a modalidade da educação a distância há muito tem utilizado as potencialidades das emergentes tecnologias digitais de forma exitosa no processo de ensino e aprendizagem. Hernandes (2017) assevera que a relação unidirecional outrora utilizada nos modelos tradicionais de educação a distância evoluiu com o aparecimento da educação online, pois as tecnologias digitais possibilitaram elevado nível de interação dialógica entre educador e educando, permitindo "encontros virtuais entre todos os participantes do processo educativo na rede social" (p. 287).

Entretanto, ainda que a utilização das tecnologias digitais não seja algo propriamente novo no campo da Educação, a pandemia escancarou lacunas nas competências digitais de professores, visto que muitos não estavam preparados para implementar metodologias de ensino em consonância com as especificidades do ciberespaço educativo, como revelaram os estudos de Dias-Trindade \& Santo (2021).

Ora, a Base Nacional Comum Curricular (BNCC), ao estabelecer as aprendizagens preconizadas para a Educação Básica no Brasil, define que as decisões pedagógicas devem fundamentar-se no desenvolvimento de competências mediante a seleção, produção, aplicação e avaliação de recursos didáticos e tecnológicos para apoiar o processo de ensino e aprendizagem, para que os estudantes sejam capazes de utilizar criticamente as tecnologias digitais "nas diversas práticas sociais (incluindo as escolares) para se comunicar, acessar e disseminar informações, produzir conhecimentos, resolver problemas e exercer protagonismo e autoria na vida pessoal e coletiva" (Brasil, 2017, p. 9).

Diante do debate acima posto, este estudo objetiva analisar as competências digitais demandadas para os professores, embasando-se na autorreflexão da sua práxis educativa, mapeando-se as eventuais lacunas apresentadas com vistas à proposição de indicativos para a formação continuada docente. A pesquisa fundamenta-se na proposta do quadro comum para a autoavaliação das competências digitais dos professores (DigCompEdu), elaborado pelo Serviço de Ciência e Conhecimento da Comissão Europeia (EU Science Hub), conforme apresentado por Redecker (2017). 
Dessa forma, o estudo configura-se como uma pesquisa descritiva, com abordagem quantitativa, utilizando-se, como instrumento de coleta de dados, a escala de autoavaliação das competências digitais dos professores (DigCompEdu Checkln), realizada entre 2020/2021 com 145 professores brasileiros da Educação Básica no Brasil, atuantes nos Anos Iniciais do Ensino Fundamental (10. ao 5o. ano).

\section{TECNOLOGIAS, COMPETÊNCIAS DIGITAIS E FORMAÇÃO DOCENTE NO BRASIL}

Para compreendermos as lacunas formativas voltadas para o uso pedagógico das tecnologias digitais é importante percebermos o contexto de formação dos docentes que atuam nos Anos Iniciais do Ensino Fundamental nas escolas públicas brasileiras. Ao longo do século $X X$, o que imperou nos cursos de formação de professores no Brasil foi uma formação sustentada no ideal de racionalidade técnica. Essa racionalidade hierarquizava o conhecimento aprendido na academia, tornando o futuro profissional da educação, que atuaria nas salas de aula, um docente reprodutor de conhecimento historicamente selecionado pelos livros didáticos e material pedagógico hegemônico (Lima, 2019).

A partir dessa perspectiva, podemos indagar: a formação desses estudantes que estão sendo formados para serem professores, perpassa pelos usos pedagógicos das tecnologias? Diante dessa pergunta, podemos sustentar que em um país em que ainda há uma quantidade extensa de professores leigos (sem formação específica para a docência), a resposta é negativa.
Estudos realizados na primeira década do século corrente nos apontam que

22\% dos 2.101 .408 professores brasileiros - 450.874 - não chegaram à universidade. Desse total, 8.339 terminaram apenas o ensino fundamental, 115.456 concluíram o ensino médio regular e 335.418, o magistério. Entre os 1,6 milhão de diplomados, 223.777 não cursaram licenciatura, modalidade que prepara professores. (Figueiredo, 2013, p. 88)

Destarte, ao analisar as estruturas curriculares dos cursos de graduação responsáveis pela formação dos futuros docentes, da Universidade Federal do Recôncavo da Bahia, localizada no Recôncavo Baiano, Brasil, inferimos que quando este debate é posto, o é por meio de uma disciplina específica, denominada de forma genérica de Tecnologias da Informação e Comunicação, de caráter não obrigatório. Nesse sentido, não há uma preocupação em formar professores preparados para mediar a aprendizagem de crianças nativas digitais em uma sociedade tecnológica.

Assim, como esperar, em um contexto em que necessitamos sobremaneira dos saberes tecnológicos inter-relacionando-os com os saberes pedagógicos, curriculares e de conteúdo, que os professores, dessa etapa da Educação Básica, possam "tranquilamente" se (re)fazerem mediadores de uma aprendizagem online, por meio de ambientes virtuais? Não há como requerer de um profissional uma habilidade não desenvolvida seja em seus cursos iniciais de formação docente.

Em seu levantamento acerca da formação do professor e das políticas a ela relacionadas, Gatti, Barreto e André (2011) evidenciaram que as formações oferecidas aos docentes 
são, em boa parte, negligenciadas e oferecidas de forma pontual e distante da realidade dos professores. (Souza \& Schneide, 2016, p. 419)

Não obstante, houve um certo investimento em aquisição de televisores, computadores, equipamentos de projeção de imagens, montagem de laboratórios de informática por parte dos sucessivos governos brasileiros, desde finais do século XX. No entanto, não houve paralelamente uma formação adequada nos cursos de ensino superior, sejam eles no âmbito da formação inicial, ou no âmbito dos cursos de pós-graduação (Mestrado e Doutorado) voltados para a área da Educação, para que, assim, os docentes se apropriassem desses espaços e de todas as suas potencialidades.

No âmbito da pós-graduação, nos referindo, mais especificamente, aos cursos de especialização, denominados no Brasil de pós-graduação lato sensu, há ainda um número muito insignificante de cursos voltados para o debate das Tecnologias Digitais e seus usos na educação nas instituições públicas e gratuitas de ensino superior.

Frente a isso, o investimento tecnológico nas/ para escolas ao longo dos anos, tornou-se, em alguma medida, inútil, visto que os docentes não estão preparados, frequentemente, não se sentem preparados ou possuem dificuldades em levar as tecnologias para o cotidiano de suas salas de aula. Tais dificuldades impedem a transformação para um ensino em que o conhecimento é construído colaborativamente e que considera os saberes prévios tecnológicos apresentados pelas crianças do século XXI, em contraponto ao ensino tradicional, pautado meramente na técnica.
Lima (2019), considerando os estudos de Tardif (2011) nos coloca que a aprendizagem dos saberes é demorada e complexa.

[...] exigindo, por consequência, uma formalização e a sistematização adequadas, no processo de ensino, para que o processo de aprendizagem ocorra concebendo-se a formação dos docentes como algo essencial à produção e atualização destes saberes. (p. 67)

Pesquisas como a de Lima (2019) nos apresentam a fragilidade da formação dos docentes que atuam nos Anos Iniciais do Ensino Fundamental no Brasil, quando se consideram os saberes curriculares e específicos das áreas de conhecimento, visto que estes docentes são considerados professores multidisciplinares, ou seja, são responsáveis por ministrar as diversas disciplinas que compõem o currículo desta etapa de ensino.

Ainda considerando o estudo de Lima (2019), é possível perceber que as/os docentes informantes não mencionam os saberes tecnológicos, visto que estes são desconsiderados em suas práticas pedagógicas, seja pela total ausência de uma formação inicial em seus cursos de ensino superior, seja pela invisibilidade da necessidade de constituir uma prática pedagógica sustentada também pelo uso das tecnologias, ou mesmo, pelas ausências de condições materiais (computadores, internet, laboratórios) para que as tecnologias se façam presentes no cotidiano da aprendizagem escolar.

Desse modo, a formação inicial para o uso pedagógico das tecnologias, feito de forma inovadora, significativa e instigadora da aprendizagem ainda é um desafio diante da denominada sociedade globalizada, do conhecimento ou da informação. A ausência dessa formação, por- 
tanto, incide sobre professores não alfabetizados em conhecimentos e habilidades midiáticas e informacionais, fato ainda mais evidente no contexto da pandemia da Covid 19.

Esses docentes, migrantes digitais, de acordo com Figueiredo (2013) não terão capacidade de empoderar seus estudantes, nativos digitais, para o uso do ciberespaço, da internet, dos programas, dos games, da televisão, do rádio, dentre outros, de forma a desenvolverem habilidades diversas e de se tornarem cidadãos bem informados e críticos.

Diante disso, indaga-se quais são as competências digitais que os docentes que atuam nos Anos Iniciais do Ensino Fundamental deveriam ter? Esse será o tema a ser debatido a seguir.

Mesmo considerando a polissemia do termo competências digitais, com diferentes abordagens em distintos contextos, neste estudo, contemplamos o conceito apresentado nos estudos de Sales \& Moreira (2019) ao afirmarem que,

[...] competência digital é o exercício sensorial, cognitivo, motor e afetivo das habilidades, valores, conhecimentos, informações, experiências dos sujeitos nas práticas de conhecimento, reconhecimento e uso das TIC digitais e conectadas, no sentido de tomar decisões, atitudes e agir de modo autônomo nos processos de intervenção, mediação e resolução de problemas oriundos do contexto da sociedade da aprendizagem, possibilitando a transformação, mudança social, política e econômica nos diversos cotidianos e setores da sociedade, inclusive na educação. (p. 18)

Nesse sentido, as competências digitais dos professores vão além do fetichismo da técnica em saber utilizar as interfaces digitais no contexto educativo, pois é necessário reflexão sobre sua intencionalidade pedagógica alinhada ao contexto socioeconômico, cultural e político em que educandos e educadores estão inseridos, conforme salienta Pesce (2014).

Assim sendo, as competências digitais dos professores contemplam todo o fazer pedagógico com o suporte das tecnologias digitais nos ambientes e demais espaços virtuais de aprendizagem, potencializando-se o processo de ensino e aprendizagem. No dizer de Dias-Trindade \& Ferreira (2020), as competências digitais docentes se constituem em um processo de evolução da literacia (ou letramento) para a fluência digital, afirmando que,

[...] Este construto engloba, naturalmente, a capacidade de trabalho em ambientes digitais, associando a componente pedagógica à componente tecnológica e digital. Porém, esta "competência digital" deve materializar-se na capacidade de mobilizar conhecimentos e atitudes para um uso efetivo da tecnologia digital em contexto profissional. (p. 169)

Dessa forma, neste pandêmico início do século $X X I$, a formação docente inicial (nos cursos de graduação) ou continuada (na pós-graduação e ao longo da vida) não pode desconsiderar o desenvolvimento de competências específicas para as tecnologias digitais como suporte à mediação pedagógica. Além das potencialidades das tecnologias digitais no processo educativo, também precisamos considerar que tanto educandos como educadores estão inseridos em uma sociedade hiperconectada de polegarzinhas digitais (Serres, 2015), não obstante a falta ou o acesso precarizado à rede de banda larga da internet, infelizmente ainda faz parte do 
cotidiano em muitos contextos de população marginalizada pelas políticas públicas.

Entretanto, o mero acesso a equipamentos e dispositivos digitais conectados à internet não assegura, de per si, o desenvolvimento das competências digitais, pois conforme afirma Santos (2019), no contexto do ensino online torna-se imprescindível que os professores saibam "[...] buscar e tratar a informação em rede, transformar informação em conhecimento, comunicar-se em rede, produzir textos em várias linguagens e suportes [...]" (p. 19), exigindo-Ihes competências que extrapolem ao tecnicismo e sejam capazes, sobretudo, de conduzi-los à fluência digital promotora da emancipação dos educandos que estão inseridos em uma sociedade hiperconectada e em rede.

Por outro lado, mesmo considerando-se que a maior parte dos estudantes são de uma geração denominada sábios digitais (Prensky, 2012), diante do mar de informações disponíveis online, estes precisam cada vez mais da mediação pedagógica docente para Ihes ajudar a extrapolar a utilização das tecnologias para além do entretenimento social e, sobretudo, saber "extrair um sentido da informação, perceber a diferença entre o que é importante e o que não é, e acima de tudo combinar os muitos fragmentos da informação num amplo quadro de mundo", no dizer de Harari (2018, p. 322).

Assim, especialmente nestes tempos pandêmicos e diante da complexidade da modernidade líquida aportada por Bauman (2001), os professores são requisitados para o desenvolvimento e aprimoramento contínuo de suas competências digitais, a fim de que possam utilizar as tecnologias digitais na promoção do aprendizado e da emancipação crítica e reflexiva dos estudantes. Certamente, um enorme desafio do qual os docentes não podem se furtar!

No tocante aos instrumentos avaliativos que buscam mapear o estágio de desenvolvimento e aprimoramento das competências digitais dos professores, encontramos no Brasil a chamada "Matriz de Competências Digitais CIEB", elaborada pelo Centro de Inovação para a Educação Brasileira (CIEB). A matriz consiste em uma escala de autoavaliação dos professores subdivida em 3 (três) áreas, ou seja, pedagógica, cidadania digital e desenvolvimento profissional, fornecendo subsídios capazes de nortear o desenvolvimento das competências digitais dos professores, esclarecem Sales \& Moreira (2019).

\section{Figura 1}

Competências digitais dos professores (DigCompEdu)

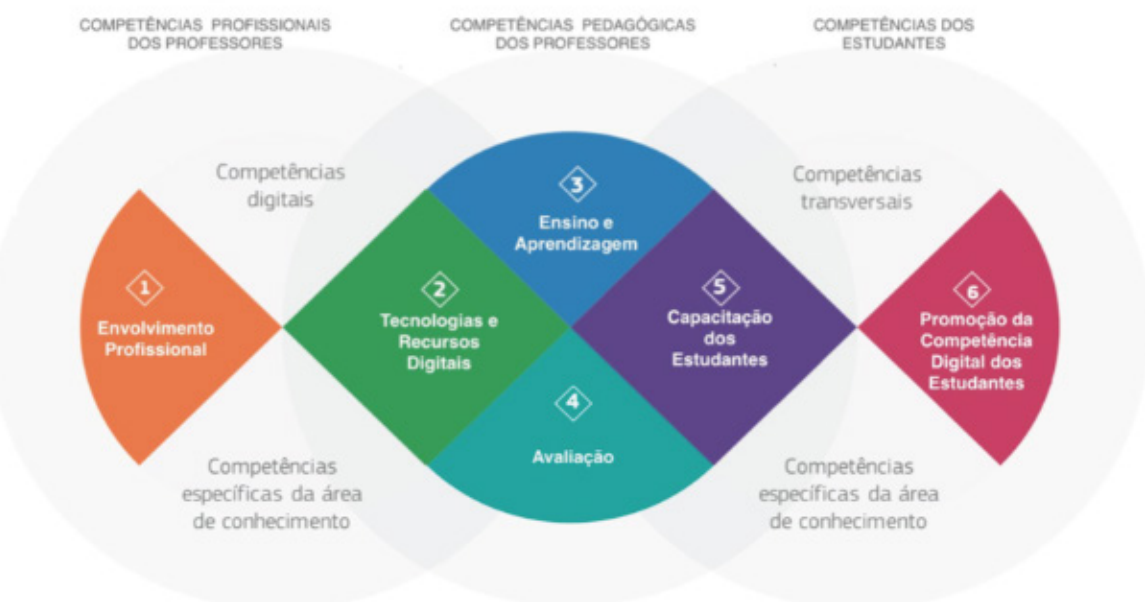

Fonte: Dias-Trindade, Moreira \& Nunes (2019); Redecker (2017) 
No contexto europeu, foi lançado em 2017 pelo Serviço de Ciência e Conhecimento da Comissão Europeia (EU Science Hub) um Quadro Comum para Competências Digitais dos Professores, denominado DigCompEdu. Fundamentado em um modelo teórico, o DigComEdu considera as especificidades do fazer pedagógico com o suporte das potencialidades das tecnologias digitais de informação e comunicação (TDIC) no processo de ensino e aprendizagem, aponta Redecker (2017). Na Figura 1, verificamos as áreas de competências digitais abarcadas pelo DigCompEdu com os seus desdobramentos (Tabela 1).

No modelo DigCompEdu, as áreas de competências digitais estão alocadas em 3 (três) níveis que se subdividem em 6 (seis) áreas competências, conforme evidenciado na Tabela 1.

Para a autoavaliação das competências digitais, o modelo DigCompEdu está estruturado no formato de um questionário autorreflexivo, classificando o estágio ou nível de desenvolvimento das competências digitais, em função do escore alcançado, conforme delineado no Tabela 2; além de fornecer devolutivas individuais com sugestões para a melhoria da práxis docente, enriquecida pelo uso das tecnologias digitais (Dias-Trindade \& Santo, 2021).

Assim, observamos que o modelo de autoavaliação das competências digitais dos professores DigCompEdu extrapola o mero mapeamento do nível em que os professores se encontram, pois fornece devolutivas norteadoras para que estes sejam capazes de avançar para os níveis subsequentes, com vistas à fluência digital. Os autores Dias-Trindade e Ferreira (2020) asseveram que o questionário também permite aferir qual tipo de formação poderá ser mais adequada a cada professor,
Tabela 1

Níveis e áreas de competências digitais DigCompEdu

\begin{tabular}{|c|c|c|}
\hline $\begin{array}{l}\text { Nível de } \\
\text { compe- } \\
\text { tência }\end{array}$ & $\begin{array}{l}\text { Área de com- } \\
\text { petência }\end{array}$ & Descrição \\
\hline \multirow{2}{*}{$\begin{array}{l}\text { Compe- } \\
\text { tências } \\
\text { profissio- } \\
\text { nais do } \\
\text { docente }\end{array}$} & $\begin{array}{l}\text { Envolvimento pro- } \\
\text { fissional }\end{array}$ & $\begin{array}{l}\text { Uso de tecnolo- } \\
\text { gias digitais para } \\
\text { comunicar, cola- } \\
\text { borar e promover } \\
\text { o desenvolvimen- } \\
\text { to profissional. }\end{array}$ \\
\hline & $\begin{array}{l}\text { Tecnologias e re- } \\
\text { cursos digitais }\end{array}$ & $\begin{array}{c}\text { Uso de tecno- } \\
\text { logias para se- } \\
\text { lecionar, criar e } \\
\text { partilhar recursos } \\
\text { digitais. }\end{array}$ \\
\hline \multirow{3}{*}{$\begin{array}{l}\text { Compe- } \\
\text { tências } \\
\text { pedagógi- } \\
\text { cas }\end{array}$} & $\begin{array}{c}\text { Ensino e aprendi- } \\
\text { zagem }\end{array}$ & $\begin{array}{c}\text { Capacidade de } \\
\text { gerir e organizar } \\
\text { o uso de tecno- } \\
\text { logias digitais } \\
\text { no processo de } \\
\text { ensino e aprendi- } \\
\text { zagem. }\end{array}$ \\
\hline & Avaliação & $\begin{array}{l}\text { Forma de recorrer } \\
\text { às tecnologias } \\
\text { digitais para ava- } \\
\text { liar e/ou melhorar } \\
\text { os processos } \\
\text { avaliativos dos } \\
\text { estudantes. }\end{array}$ \\
\hline & $\begin{array}{l}\text { Empoderamento } \\
\text { dos estudantes }\end{array}$ & $\begin{array}{l}\text { Uso das tecno- } \\
\text { logias para mel- } \\
\text { horar a inclusão, } \\
\text { personalização e } \\
\text { engajamento dos } \\
\text { estudantes. }\end{array}$ \\
\hline $\begin{array}{l}\text { Desenvol- } \\
\text { vimento } \\
\text { das com- } \\
\text { petências } \\
\text { dos estu- } \\
\text { dantes }\end{array}$ & $\begin{array}{l}\text { Promoção da com- } \\
\text { petência digital dos } \\
\text { estudantes }\end{array}$ & $\begin{array}{c}\text { Subsidiar os es- } \\
\text { tudantes no uso } \\
\text { das tecnologias } \\
\text { digitais de forma } \\
\text { criativa e respon- } \\
\text { sável. }\end{array}$ \\
\hline
\end{tabular}

Fonte: Adaptado de Ota \& Dias-Trindade (2020) e Redecker (2017). 
isto é, as áreas em que precisa dedicar-se à sua formação continuada, bem como aquelas em que se encontra mais próximo de um nível de fluência digital.

\section{Tabela 2}

Niveis de competências digitais no modelo DigCompEdu

\begin{tabular}{|c|c|}
\hline Nível de competência & Perfil \\
\hline $\begin{array}{l}\text { A1 - Recém chegado } \\
\text { (até } 20 \text { pontos) }\end{array}$ & \multirow{2}{*}{$\begin{array}{c}\text { Assimilam novas informações } \\
\text { e desenvolvem práticas di- } \\
\text { gitais básicas no seu fazer } \\
\text { pedagógico. }\end{array}$} \\
\hline $\begin{array}{c}\text { A2 - Explorador } \\
\text { (entre } 20 \text { e } 33 \text { pontos) }\end{array}$ & \\
\hline $\begin{array}{c}\text { B1 - Integrador } \\
\text { (entre } 34 \text { a } 49 \text { pontos) }\end{array}$ & \multirow{2}{*}{$\begin{array}{c}\text { Aplicam, expandem e refle- } \\
\text { tem criticamente em suas } \\
\text { práticas pedagógicas com a } \\
\text { utilização das TDIC. }\end{array}$} \\
\hline $\begin{array}{c}\text { B2 - Especialista } \\
\text { (entre } 50 \text { e } 65 \text { pontos) }\end{array}$ & \\
\hline $\begin{array}{c}\text { C1 - Líder } \\
\text { (entre } 66 \text { e } 80 \text { pontos) }\end{array}$ & \multirow{2}{*}{$\begin{array}{l}\text { Compartilham seus conheci- } \\
\text { mentos, refletem criticamente } \\
\text { e desenvolvem novas práticas } \\
\text { com as tecnologias digitais. }\end{array}$} \\
\hline $\begin{array}{c}\text { C2 - Pioneiro } \\
\text { (acima de } 80 \text { pontos) }\end{array}$ & \\
\hline
\end{tabular}

Fonte: Adaptado de Dias-Trindade \& Santo (2021).

Neste estudo, utilizamos o modelo de autoavaliação das competências digitais DigCompEdu, considerando-se o seu aporte teórico e sua estruturação, além das suas potencialidades no tocante às devolutivas aos professores, bem como os indicativos para formação continuada nas lacunas encontradas.

\section{PROCEDIMENTOS METODOLÓGICOS}

Este estudo configura-se como uma pesquisa descritiva, com abordagem quantitativa, tendo como procedimento de coleta de dados o levantamento (survey), operacionalizado por meio de um questionário eletrônico. De acordo com Prodanov \& Freitas (2013), as pesquisas descritivas delineiam as características do fenômeno observado buscando classificar, explicitar e interpretar os fatos por meio de técnicas padronizadas de coleta de dados.

Nesse sentido, utilizamos a versão brasileira da escala DigCompEdu Checkln, originalmente desenvolvida no âmbito do EU Science Hub, cuja validação para a língua portuguesa foi realizada pelos autores Dias-Trindade, Moreira \& Nunes (2019). Trata-se de um questionário que contempla 21 (vinte e uma) questões de autoavaliação das competências digitais dos professores, aplicáveis a todos os níveis de ensino, subdivididas nas 6 (seis) áreas do modelo DigCompEdu.

Para cada uma das 21 competências do instrumento DigCompEdu Checkln, apresenta-se uma afirmação ou item de competência e os participantes devem selecionar uma das cinco opções que melhor caracterize sua posição em relação à afirmação. As opções escolhidas são pontuadas variando de 0 , para a primeira resposta, a 4 pontos, para a última, totalizando 84 pontos possíveis no instrumento, resultando assim na classificação do escore de competência, apresentado na Tabela 2 (Dias-Trindade \& Moreira, 2020; Dias-Trindade \& Santo, 2021).

Ressalta-se que Dias-Trindade, Moreira \& Nunes (2019) realizaram a validação estatística do instrumento DigCompEdu Checkln e concluíram que ele apresenta bons indicadores globais de validade, "com estruturas fatoriais interpretáveis, pressupondo, portanto, que avaliam, de forma consistente, as variáveis que pretendem medir, constituindo-se como uma escala capaz de contribuir para a avaliação das competências digitais dos professores" (p. 157).

Os participantes do estudo foram convidados a acessar voluntariamente a plataforma DigCompEdu-UFRB, desenvolvida na interface digital EU Survey, no âmbito da Rede Colaborativa de Aprendizagem (RCA). A pesquisa foi realizada 
entre os meses de março de 2020 a março de 2021, alcançando 145 professores brasileiros respondentes oriundos da Educação Básica, todos atuantes nos Anos Iniciais do Ensino Fundamental (EF1), isto é, do $1^{\circ}$. ao $5^{\circ}$. ano.

Em atendimento às resoluções do Conselho Nacional de Ética em Pesquisa (CONEP), que fornecem as diretrizes éticas brasileiras para pesquisas com participantes humanos, o projeto de pesquisa foi submetido e aprovado pelo Comitê de Ética em Pesquisa (CEP), da Universidade Federal do Recôncavo da Bahia (UFRB), e aprovado sob o parecer n. 3.582.41.

\section{RESULTADOS}

A pesquisa contemplou a participação de 145 professores respondentes da educação básica que se constituíram na amostra para as análises desse estudo, sendo $118(81,4 \%)$ do gênero feminino, $26(17,9 \%)$ do gênero masculino e 1 (0,7\%) não binário.

Os participantes apresentaram média ponderada de 39,8 anos, contemplando-se idades entre 24 a 63 anos. Destaca-se que 82 (56,5\%) respondentes estão na faixa de idade entre 32 a 43 anos.

No tocante à área de formação, destacamos que a maioria, isto é, 93 (64,1\%) participantes são oriundos da área de Ciências Humanas e $36(24,8 \%)$ da Linguística, Letras e Artes, sendo o restante subdivididos entre as áreas das Ciências Agrárias, Biológicas, Saúde, Exatas e da Terra.

Em relação à formação continuada em nível de pós-graduação, observamos na Tabela 3 que 97 (66,9\%) participantes possuem curso de especialização lato sensu, sendo indicativo de interesse na formação e aperfeiçoamento. Ademais, 88 (60,7\%) participantes da pesquisa atuam na rede pública municipal ou estadual de ensino, sendo a realização de cursos de especialização frequentemente exigida nos planos de progressão funcional.

Todavia, os dados revelam que 33 (22,8\%) participantes ainda não possuem nenhuma pós-graduação. Ressalta-se que no Brasil os cursos de pós-graduação em nível de mestrado e doutorado não possuem acesso universal, em virtude das limitações no número de vagas ofertadas, resultando em processos seletivos amiúde concorridos.

\section{Tabela 3}

Formação continuada dos participantes (pós-graduação)

\begin{tabular}{|c|c|c|}
\hline $\begin{array}{c}\text { Formação na } \\
\text { pós-graduação }\end{array}$ & $\begin{array}{c}\text { Número } \\
\text { docentes }\end{array}$ \\
\hline Não possui & 33 & $22,76 \%$ \\
\hline Especialização & 97 & $66,90 \%$ \\
\hline Mestrado / Doutorado & 15 & $10,34 \%$ \\
\hline
\end{tabular}

Todos os participantes atuam nos Anos Iniciais da Educação Básica no Brasil, sendo que 87 (60\%) exercem suas atividades docentes no estado da Bahia; 12 (8,3\%) no estado de Sergipe; $9(6,2 \%)$ no estado de Minas Gerais e o restante subdivididos entre os estados de São Paulo, Ceará, Mato Grosso, Espírito Santo e Rio de Janeiro.

\section{Tabela 4}

Tempo de experiência docente dos participantes

\begin{tabular}{|c|c|c|c|}
$\begin{array}{c}\text { Tempo de do- } \\
\text { cência (anos) }\end{array}$ & $\begin{array}{c}\text { Número de } \\
\text { docentes }\end{array}$ & $\%$ & $\begin{array}{c}\% \text { acu- } \\
\text { mulado }\end{array}$ \\
\hline até 06 & 53 & $36,55 \%$ & $36,55 \%$ \\
\hline 06 a 12 & 35 & $24,14 \%$ & $60,69 \%$ \\
\hline acima 12 & 57 & $39,31 \%$ & $100,0 \%$ \\
\hline
\end{tabular}

Na Tabela 4, observamos que a amostra contemplou 53 (36,55\%) professores iniciantes com até 06 anos de tempo na docência, bem 
como 57 (39,31\%) professores com mais de 12 anos no magistério.

\section{DISCUSSÃO}

Considerando-se os dados coletados com o instrumento de autoavaliação DigCompEdu Checkln, na média geral, a amostra de professores respondentes alcançou escore médio de 40,9 pontos, classificando-os na categoria B1 integrador.

De acordo com Lucas \& Moreira (2018), os integradores já utilizam uma variedade de tecnologias digitais nas suas práticas e estão dispostos a expandir o seu repertório. Entretanto, os autores apontam que estão na etapa de analisar quais as interfaces e tecnologias digitais funcionam melhor em função dos métodos e estratégias pedagógicas que desejam implementar. "No entanto, os Integradores só precisam de mais algum tempo para experimentarem e refletirem, complementado por incentivo colaborativo e troca de conhecimento para se tornarem Especialistas" (p.30), asseveram os autores.

O nível geral de competência digital revelado pelos professores respondentes coaduna-se com os resultados encontrados nos estudos de Dias-Trindade \& Moreira (2018), em uma amostra com 147 professores do Ensino Fundamental e Médio em Portugal. Nesse estudo, o escore médio dos professores foi de 49,0 pontos, classificando-os como B1 - Integrador; contudo, bem próximo ao nível B2 - Especialista, que se inicia com 50 pontos.

Classificação similar também foi observada com 182 docentes do ensino superior no Brasil, na região do Recôncavo da Bahia, com resultado médio de 41 pontos, classificando-os no nível B1 - Integrador (Dias-Trindade \& Santo, 2021). Outro estudo com 141 docentes brasileiros do
Ensino Básico, Técnico e Tecnológico, realizado no Estado do Tocantins, alcançou o mesmo nível geral de competência digital (Melo, 2019).

Tais estudos das competências digitais dos professores, utilizando a mesma escala de autoavaliação DigCompEdu Checkln, revelam que os professores do Ensino Fundamental ao Superior se deparam com o desafio urgente de desenvolver e de aperfeiçoar suas competências com vistas à fluência digital, a fim de não se tornarem alienígenas digitais inseridos em uma sociedade hiperconectada.

Na Tabela 5, observamos em detalhe as médias de respostas para cada uma das 21 competências, sendo que as dimensões relacionadas com as competências profissionais docente e a competência dos estudantes são aquelas que apresentam maiores lacunas que precisam de enfrentamento por meio da formação continuada.

Ao analisarmos detalhadamente a média dos itens de competências, verificamos que tão somente 1 (um) item de competência foi considerado bom (com valor médio acima de 2,50 pontos), relacionado com a participação em programas de formação online, revelando a preocupação da amostra de professores com sua formação continuada. Também apresentam 7 (sete) itens com resultados medianos (com valores médios entre 2,49 e 2,0 pontos).

Por fim, na pesquisa, temos um grupo recém ingresso no magistério (36,55\%) e um grupo mais antigo (39,31\%). Destacamos, em relação a esse dado, um fenômeno importante: o tempo de atuação na docência não se constitui, por si só, em indicador do nível de experiência ou de capacidade de reflexão sobre sua prática docente com o uso das tecnologias digitais, pois a experiência é resultante da capacidade docente em refletir constantemente sobre sua práxis pedagógica de forma crítica. 
Tabela 5

Resultados gerais da amostra por nível de competência

\begin{tabular}{|c|c|c|c|c|}
\hline Dimensão & Área & $\begin{array}{l}\text { Item avaliado da com- } \\
\text { petência digital }\end{array}$ & $\begin{array}{l}\text { Média pon- } \\
\text { derada }\end{array}$ & $\begin{array}{l}\text { Valoração } \\
\text { do nível }\end{array}$ \\
\hline \multirow{6}{*}{$\begin{array}{l}\text { Competências } \\
\text { profissionais do- } \\
\text { cente }\end{array}$} & \multirow{4}{*}{$\begin{array}{l}\text { Envolvimento profis- } \\
\text { sional }\end{array}$} & $\begin{array}{l}\text { 1. Uso de diferentes canais de } \\
\text { comunicação }\end{array}$ & 2,39 & Médio \\
\hline & & $\begin{array}{l}\text { 2. Desenvolvimento contínuo } \\
\text { digital }\end{array}$ & 2,01 & Médio \\
\hline & & $\begin{array}{l}\text { 3. Participação de formação } \\
\text { online }\end{array}$ & 3,12 & Bom \\
\hline & & $\begin{array}{l}\text { 4. Pesquisa online em busca por } \\
\text { estratégias e recursos }\end{array}$ & 2,12 & Médio \\
\hline & \multirow{2}{*}{$\begin{array}{l}\text { Tecnologias e recur- } \\
\text { sos digitais }\end{array}$} & $\begin{array}{l}\text { 5.Uso de tecnologias no trabalho } \\
\text { interno/externo }\end{array}$ & 1,87 & Fraco \\
\hline & & $\begin{array}{l}\text { 6. Segurança e proteção de con- } \\
\text { teúdo pessoal }\end{array}$ & 2,34 & Médio \\
\hline \multirow{10}{*}{$\begin{array}{c}\text { Competências } \\
\text { pedagógicas do- } \\
\text { cente }\end{array}$} & \multirow{5}{*}{$\begin{array}{l}\text { Ensino e aprendi- } \\
\text { zagem }\end{array}$} & 7. Ensino & 2,21 & Médio \\
\hline & & 8. Orientação & 2,02 & Médio \\
\hline & & 9. Aprendizagem colaborativa & 1,68 & Muito fraco \\
\hline & & 10. Metodologias digitais ativas & 1,85 & Fraco \\
\hline & & $\begin{array}{l}\text { 11. Atividades com criação de } \\
\text { conteúdo digital }\end{array}$ & 1,78 & Fraco \\
\hline & \multirow{3}{*}{ Avaliação } & 12. Avaliação autorregulada & 1,57 & Muito fraco \\
\hline & & $\begin{array}{l}\text { 13. Estratégias avaliativas diver- } \\
\text { sas }\end{array}$ & 1,82 & Fraco \\
\hline & & 14. Feedback e planejamento & 1,69 & $\begin{array}{l}\text { Muito } \\
\text { Fraco }\end{array}$ \\
\hline & \multirow{2}{*}{$\begin{array}{l}\text { Empoderamento } \\
\text { dos estudantes }\end{array}$} & $\begin{array}{l}\text { 15. Análise das evidências para } \\
\text { fornecer apoio }\end{array}$ & 2,20 & Médio \\
\hline & & $\begin{array}{l}\text { 16. Auxílio com problemas tec- } \\
\text { nológicos }\end{array}$ & 1,92 & Fraco \\
\hline \multirow{5}{*}{$\begin{array}{l}\text { Competências } \\
\text { discente }\end{array}$} & \multirow{5}{*}{$\begin{array}{l}\text { Promoção das com- } \\
\text { petências digitais } \\
\text { dos estudantes }\end{array}$} & $\begin{array}{l}\text { 17. Atividades adaptadas aos } \\
\text { discentes }\end{array}$ & 1,72 & Fraco \\
\hline & & $\begin{array}{c}\text { 18. Orientações para Identificar } \\
\text { notícias falsas }\end{array}$ & 1,95 & Fraco \\
\hline & & $\begin{array}{l}\text { 19. Comunicação interna/ex- } \\
\text { terna }\end{array}$ & 1,77 & Fraco \\
\hline & & $\begin{array}{l}\text { 20. Comportamento responsável } \\
\text { online }\end{array}$ & 1,65 & Muito fraco \\
\hline & & $\begin{array}{l}\text { 21. Resolução de problemas } \\
\text { concretos com tecnologias }\end{array}$ & 1,74 & Fraco \\
\hline
\end{tabular}

Nota: escala utilizada na valorização para o nível do item de competência: Bom - acima de 2,5 pontos; médio, entre 2,49 e 2,0 pontos; fraco, entre 1,99 a 1,70 pontos; muito fraco, abaixo de 1,70 pontos. 
Observamos na Tabela 5 que os professores respondentes apresentaram 9 (nove) itens de competências no nível considerado fraco (com valores médios entre 1,99 a 1,70 pontos), englobando as áreas de tecnologias e recursos digitais, ensino e aprendizagem, avaliação, empoderamento e desenvolvimento das competências digitais dos estudantes.

Ademais, 4 (quatro) itens de competências estão no nível considerado muito fraco (abaixo de 1,70 pontos), ou seja, I) aprendizagem colaborativa: estímulo para que os estudantes trabalhem em grupo, utilizando as tecnologias digitais para gerar e documentar os dados que apresentam; II) avaliação autorregulada, por meio do uso das tecnologias digitais para permitir que os estudantes planejem, documentem e acompanhem as suas aprendizagens de forma autônoma; III) feedback e planejamento: uso das tecnologias digitais para fornecer feedback efetivo e IV) comportamento responsável online: recomendações e orientações aos estudantes para se comportar de forma segura e responsável nos espaços online.

Assim, os 04 (quatro) itens de competências supracitados considerados "muito fracos" juntamente com os 09 (nove) itens classificados como "fracos" se constituem nos pontos prioritários de competências digitais, nos quais os professores pesquisados apresentam lacunas específicas que necessitam ser emergencialmente suprimidas mediante ações de formação continuada em tais temáticas. No dizer de Figueiredo (2013), sem o desenvolvimento de tais competências digitais, os professores dificilmente terão êxito em desenvolver nos seus estudantes o empoderamento para o uso reflexivo e crítico do ciberespaço, promovendo o aprendizado e a autonomia.

\section{Tabela 6}

Relação das competências digitais com a formação docente

\begin{tabular}{|c|c|c|c|}
$\begin{array}{c}\text { Formação } \\
\text { em nível de } \\
\text { pós-graduação }\end{array}$ & $\begin{array}{c}\text { Núme- } \\
\text { ro do- } \\
\text { centes }\end{array}$ & Escore & Categoria \\
\hline Não possui & 33 & 42,5 & $\begin{array}{c}\text { B1 - Integra- } \\
\text { dor }\end{array}$ \\
\hline $\begin{array}{c}\text { Especialização } \\
\text { Mestrado / Dou- } \\
\text { torado }\end{array}$ & 15 & 47,9 & $\begin{array}{c}\text { B1 - Integra- } \\
\text { dor }\end{array}$ \\
\hline
\end{tabular}

Conforme evidenciado na Tabela 6, os dados coletados com os professores respondentes também revelaram que a formação continuada em nível de pós-graduação obteve pequeno impacto na classificação da categoria de competências digitais entre os professores com mestrado/doutorado.

Observamos também que a realização de cursos de especialização não impactou significativamente em relação àqueles que não a cursaram, pois os $33(22,7 \%)$ que declararam não possuir especialização alcançaram escore médio ligeiramente superior com 42,5 pontos, porém próximo aos 39,1 pontos obtidos pelos 97 (66,9\%) que possuem especialização, ambos classificados na categoria B1 - Integrador.

Ainda nesse contexto, os 15 (10,34\%) respondentes que cursaram mestrado/doutorado conseguiram alcançar escore de 48,9 pontos, sendo também classificados na categoria B1 Integrador, porém com resultado muito próximo ao nível subsequente, isto é, B2 - Especialista (a partir de 50 pontos).

Dessa forma, os dados coletados apontam para a fragilidade da formação (inicial ou continuada) dos professores brasileiros dos Anos Iniciais do Ensino Fundamental participantes neste estudo, desvelando emergentes necessidades de formação, visando o desenvolvimen- 
to das competências digitais que os conduzam à fluência digital frente ao fazer pedagógico em uma sociedade conectada e em rede, sobretudo em tempos de pandemia da Covid-19.

Nesse contexto, "[...] a formação deveria dotar o professor de instrumentos intelectuais que sejam úteis ao conhecimento e à interpretação das situações complexas em que se situa [...]" (Imbérnon, 2011, p. 42).

Não podemos desconsiderar, no cenário exposto, o nível de sucateamento das escolas da rede pública, pois frequentemente deixam de fornecer condições de infraestrutura mínima para que os planos de ensino e suas sequências didáticas sejam enriquecidas pelo uso cotidiano das tecnologias digitais, no dizer de Lucas \& Moreira (2019).

\section{CONCLUSÕES}

Neste estudo, analisamos as competências digitais demandadas pelos professores brasileiros dos Anos Iniciais do Ensino Fundamental, especialmente diante dos desafios pedagógicos impostos pela pandemia da Covid-19, tendo-se como referência o quadro comum para a autoavaliação das competências digitais dos professores (DigCompEdu).

A pesquisa realizada com 145 professores demonstrou que estes se encontram na categoria B1 - Integrador, isto é, necessitam de mais tempo para experimentar e refletir sobre a utilização das tecnologias digitais, contando com o incentivo e com a colaboração dos pares para avançar. O estudo também revelou que tais professores possuem lacunas emergenciais, especialmente nas dimensões relacionadas com as tecnologias e recursos digitais; ensino e aprendizagem; avaliação; empoderamento e desenvolvimento das competências digitais dos estudantes.
O estudo apontou a urgente necessidade de os cursos de formação inicial e continuada contemplarem os saberes relacionados com o uso pedagógico das tecnologias de forma inovadora, significativa, promotora da aprendizagem e da emancipação dos estudantes, estimulando os docentes a uma construção contínua do saber, considerando as comunidades formativas (Imbérnon, 2009).

Adicionalmente, os dados demonstraram que ainda é diminuto o impacto da formação inicial e continuada no desenvolvimento das competências digitais, revelando a necessidade de que tais saberes sejam inseridos de forma transdisciplinar na formação dos professores para que não se tornem alienígenas digitais, excluídos cada vez mais de uma educação integrada e conectada com as informações que circulam na "velocidade da luz", as quais são continuamente acessadas por grande parte de nossos estudantes dos Anos Iniciais do Ensino Fundamental.

Além das ações de formação docente concatenadas com as tecnologias digitais para a prática pedagógica, dificilmente será possível alcançar níveis satisfatórios de competências digitais para os professores sem a universalização do acesso à rede banda larga de internet e a disponibilização de equipamentos para professores e estudantes na rede pública, especialmente aqueles em situação de vulnerabilidade social.

Deve-se, por fim, destacar que há o acesso às tecnologias e o uso delas por parte dos docentes. No entanto, esse acesso e uso mostra-se precário se considerarmos as demandas da educação e da sociedade atualmente, sobretudo se considerarmos o contexto da pandemia. Retomemos, por exemplo, que esse uso em nível "bom" se dá em dimensões que se limitam a uma atuação mais no âmbito da autofor- 
mação (3,12 - Participação e formação online). Em outras dimensões, em que são necessários sujeitos mais ativos e menos passivos, considerando-se a docência e o uso das tecnologias para este exercício, as lacunas se evidenciam. Assim, contrariamente ao que se postula como ideal, temos na educação, conforme os estudos apresentados, docentes ainda passivos na relação com o uso das tecnologias para fins didático-pedagógicos na complexidade desse fazer. Esse fazer para ocorrer de forma articulada com nossa época deve aliar a tradicional aula expositiva, o giz, a lousa e a sala de aula física, por exemplo, a outras unidades de tempo e lugar (o virtual) e suas potencialidades tecno- lógicas disponíveis. Do contrário, a prática pedagógica ficará relegada a um anacronismo e perderá oportunidades de se reinventar com seu tempo.

Estejamos atentos para que não seja ampliado o fosso da desigualdade social e do acesso às tecnologias, que assola o Brasil e demais países pobres e em desenvolvimento. Urge que tenhamos políticas públicas efetivas para a inclusão e formação digital dos professores! 


\section{REFERÊNCIAS}

Bauman, Z. (2001). Modernidade líquida. Jorge Zahar.

Brasil (2017). Base Nacional Comum Curricular. Brasília, Ministério da Educação. http://basenacionalcomum.mec.gov.br/abase/\#introducao

Dias-Trindade, S., \& Santo, E. E. (2021). Competências digitais de docentes universitários em tempos de pandemia: análise da autoavaliação Digcompedu. Práxis Educacional, 17(45), 1-17. https://doi.org/10.22481/ praxisedu.v17i45.8336

Dias-Trindade, S., \& Ferreira, A. G. (2020). Digital teaching skills: DigCompEdu Checkln as an evolution process from literacy to digital fluency, Icono 14 Revista Científica de Comunicación y Tecnologías Emergentes, 18(2), $162-$ 187.

Dias-Trindade, S., \& Moreira, J. A. (2020). Assessment of high school teachers on their digital competences. magis, Revista Internacional de Investigación en Educación, 13, 1-21. https://doi.org/10.11144/Javeriana.m13.ahst

Dias-Trindade, S., Moreira, J. A., \& Nunes, C. S., (2019). Escala de autoavaliação de competências digitais de professores. Procedimentos de construção e validação. Texto Livre: Linguagem e Tecnologia, 12(2), 152-171. https://doi.org/10.17851/1983-3652.12.2.152-171

Dias-Trindade, S., \& Moreira, J. (2018). Avaliação das competências e fluência digitais de professores no ensino público médio e fundamental em Portugal. Revista Diálogo Educacional, 18(58), 624-644. http://dx.doi.org/10.7213/1981-416X.18.058.DS02

Figueiredo, M. A. (2013). Conhecimento, tecnologia e formação de professores. En Pimentel, S.C. Lopes, A. L. Souza, L. D. A. dos. (Coords.), Formação de Professores: políticas, saberes e práticas. (pp. 83-108). Shekinah Editora.

Harari, Y. N. (2018). 21 lições para o século 21. Companhia das Letras.

Hernandes, P. R. (2017). A Universidade Aberta do Brasil e a democratização do Ensino Superior público. Ensaio: Avaliação e Políticas Públicas em Educação, 25(95), 283-307. Epub April 27, 2017. https://doi.org/10.1590/ s0104-40362017002500777

Imbérnon, F. (2011). Formação docente e profissional: formar-se para a mudança e a incerteza. Cortez Editora.

Imbérnon, F. (2009). Formação permanente do professorado: novas tendências. Cortez Editora.

Lima, T. P. P. de. (2019). Entrelaçando Saberes e práticas: a história ensinada no $5^{\circ}$ ano do Ensino Fundamental. CRV Editora. 
Lucas, M., \& Moreira, A. (2018). DigCompEdu: quadro europeu de competência digital para educadores. Aveiro, UA.

Melo, I. B. (2019). Avaliação do nível de proficiência digital de professores do Instituto Federal do Tocantins (IFTO) Campus Palmas e Porto Nacional. [Dissertação, Mestrado Profissional em Gestão de Políticas Públicas, Universidade Federal do Tocantins, Brasil]. Repositório UFT, Biblioteca Digital de Teses e Dissertações da UFT.

Ota, M., \& Dias-Trindade, S. (2020). Ambientes digitais de aprendizagem e competências digitais: conhecer o presente para agir num futuro pós-covid. Educação, 10(1), 211-226. https://doi.org/10.17564/2316-3 828.2020v10n1p211-226

Pesce, L. (2014). Políticas de formação inicial de professores, tecnologias e a construção social do tempo. EccoS -Rev. Cient., 33, 157-172.

Prensky, M. (2012). From Digital natives to digital wisdom: hopeful essays for 21st century learning. Corwin Press. https://www.doi. org/10.4135/9781483387765

Prodanov, C. C., \& Freitas, E. C. (2013). Metodologia do trabalho científico: métodos e técnicas da pesquisa e do trabalho acadêmico. (2. ed.). Feevale.

Redecker, C. (2017). European Framework for the Digital Competence of Educators: DigCompEdu. Luxembourg: Publications Office of the European Union.

Sales, M. V., \& Moreira, J. A. (2019). Cartografia conceitual de competência e competência digital: uma compreensão ampliada. Revista UFG, 19, $1-31$.

Santos, E. (2019). Pesquisa-formação na cibercultura. EDUFPI.

Serres, M. (2015). Polegarzinha. Bertrand Brasil.

Souza, A. A. N., \& Schneide, H. N. (2016). Tecnologias Digitais na Formação Inicial Docente: articulações e reflexões com uso de redes sociais. ETD - Educ. Temat. Digit., 18(2), 418-436.

Tardif, M. (2011). Saberes Docentes e Formação Profissional. Vozes. 